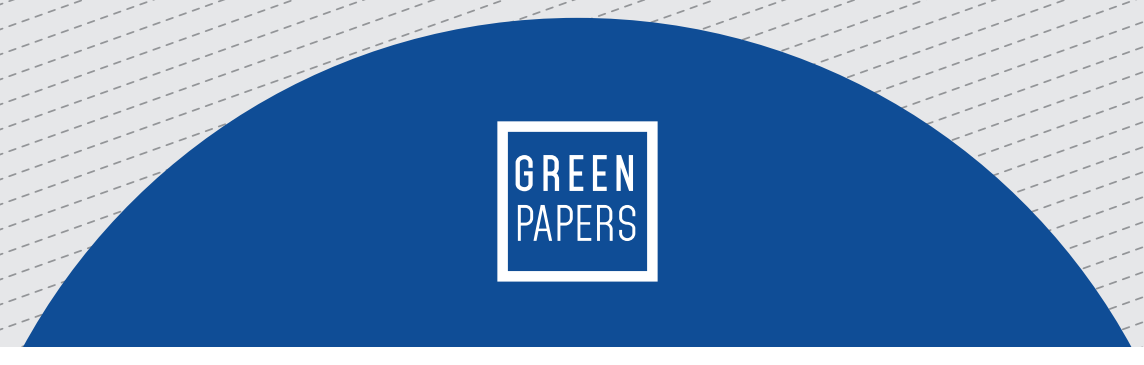

\title{
GLOSARIO SOBRE EL MODELO EDUCATIVO CRÍTICO CON ENFOQUE DE COMPETENCIAS
}

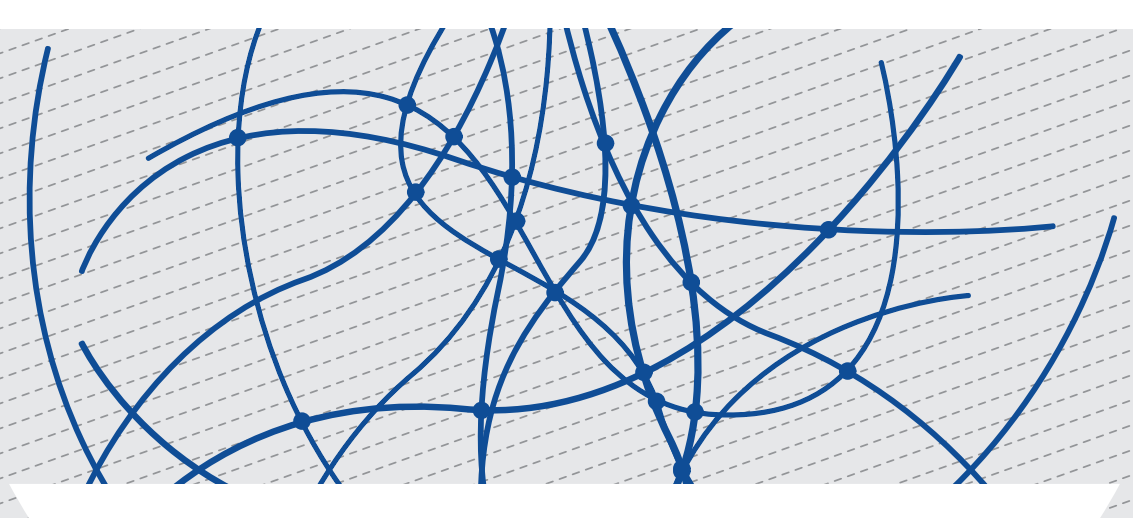

CARLOS JULIO RESTREPO-VELÁSQUEZ CLAUDIA ESPINAL-CORREA

\section{U⿺}

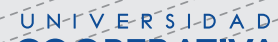
COOPERATIVA D-E $-O-O-O T-B-A-$

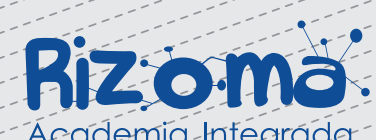

Ácádemiáa Intégráda

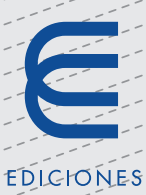

EDOICIOŃÉES 
GREEN

PAPERS

Los Green papers,

pertenecientes a la colección

Working papers de Apropiación

Social de Conocimiento,

difunden textos que abordan

desafíos, políticas o estrategias

que repercuten en los procesos

misionales de la universidad.

Busca compartir experiencias

o suscitar la discusión en la

comunidad universitaria propia,

de la región y de otras latitudes. 


\section{GLOSARIO SOBRE EL MODELO EDUCATIVO CRÍTICO CON ENFOQUE DE COMPETENCIAS}




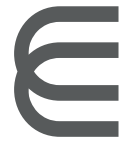

EDICIONES
Rizomà.

Academia Integrada

GLOSARIO SOBRE EL MODELO EDUCATIVO CRÍTICO CON ENFOQUE DE COMPETENCIAS

Carlos Julio Restrepo-Velásquez

Claudia Espinal-Correa

Ediciones Universidad Cooperativa de Colombia, Bogotá, octubre de 2019

Doi: https://doi.org/10.16925/wpgp.01

\author{
UNIVERSIDAD COOPERATIVA DE COLOMBIA \\ Maritza Rondón Rangel \\ Rectora \\ Alba Luz Muñoz Restrepo \\ Vicerrectora Académica \\ María Consuelo Moreno Orrego \\ Vicerrectora de Proyección Institucional \\ John Harvey Garavito Londoño \\ Vicerrector de Desarrollo Institucional \\ Hernán Darío Arenas Córdoba \\ Vicerrector Financiero \\ Claudia Espinal Correa \\ Proyecto Rizoma \\ Carlos Julio Restrepo Velásquez \\ Observatorio para la Gestión \\ del Conocimiento
}

\author{
FONDO EDITORIAL \\ Julián Pacheco Martínez \\ Director Nacional Editorial \\ Daniel Urquijo Molina \\ Especialista en Gestión Editorial \\ Camilo Moncada Morales \\ Especialista en Producción Editorial \\ (libros)
Andrés Felipe Andrade Cañón
Especialista en Producción Editorial (revistas)
Claudia Carolina Caicedo Baquero
Analista Editorial
PROCESO EDITORIAL
María Carolina Ochoa
Corrección de estilo y pruebas
Kilka Diseño Gráfico
Diagramación
Kilka Diseño Gráfico
Diseño de pauta (internas y portada)

\footnotetext{
Este documento puede ser consultado, descargado o reproducido desde nuestro repositorio institucional (https://repository.ucc.edu.co/handle/20.500.12494/7369) para uso de sus contenidos, bajo la licencia de Creative Commons Reconocimiento-No Comercial-Sin Obra Derivada 4.0 Internacional. http:// creativecommons.org/licenses/by-nc-nd/4.0/
}

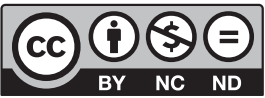




\section{ACERCA DE LOS AUTORES}

Carlos Julio Restrepo-Velásquez, comunicador social y periodista, jefe del Observatorio para la Gestión de Conocimiento, Dirección Nacional Gestión de Programas, Universidad Cooperativa de Colombia, sede Medellín, Colombia.

correo-e: carlos.restrepov@ucc.edu.co

Claudia Espinal-Correa, magíster en gestión tecnológica, líder nacional del proyecto Rizoma, Dirección Nacional de Innovación y Tecnologías Educativas, Universidad Cooperativa de Colombia, sede Medellín, Colombia.

Correo-e: claudia.espinal@ucc.edu.co

ORCID: https://orcid.org/0000-0002-4095-0495

CvLAC: https://scienti.colciencias.gov.co/cvlac/visualizador/generarCurriculoCv.do? cod_rh=0001037323

GrupLac: https://scienti.colciencias.gov.co/gruplac/jsp/visualiza/visualizagr.jsp? nro $=00000000011355$ 


\section{¿CÓMO CITAR ESTE DOCUMENTO?}

Restrepo-Velásquez, C. J. y Espinal-Correa, C. (2019). Glosario sobre el Modelo Educativo Crítico con Enfoque de Competencias (Green Paper N. ${ }^{\circ}$ 1). Bogotá: Ediciones UCC. doi: https://doi.org/10.16925/wpgp.01

NOTA LEGAL

El presente green paper ha sido incluido dentro de nuestro repositorio institucional como Apropiación social de conocimiento por solicitud del autor, con fines informativos, educativos o académicos. Asimismo, los argumentos, datos y análisis incluidos en el texto son responsabilidad absoluta del autor y no representan la opinión del Fondo Editorial o de la Universidad.

\section{DISCLAIMER}

This green paper has been uploaded to our institutional repository as Social Appropriation of Knowledge due to the request of the author. This document should be used for informational, educational or academic purposes only. Arguments, data and analysis included in this document represent authors' opinion not the Press or the University 


\section{RESUMEN}

La polisemia es uno de los fenómenos que afecta la eficacia de la comunicación en los ámbitos académicos e intelectuales, Con frecuencia, los hablantes deben realizar preguntas de confirmación para verificar que se están refiriendo a lo mismo. Se pueden relacionar algunas causas, por ejemplo, que se usan metáforas y analogías tomadas de la cotidianidad y de las redes sociales, para hablar de temas educativos formales, lo que resulta confuso la mayoría de las veces, o que el idioma, en este caso el español, no dispone de una etimología práctica y al alcance de todos para formar palabras nuevas con sentido gramatical claro, entre otras razones. Cualquiera que sea la causa, desde la perspectiva de la gestión de conocimiento, cuando se requiere iniciar un proceso de socialización de fenómenos profundamente disruptivos, es preciso disponer de un glosario, es decir, un conjunto ordenado de términos definidos y comentados que propicien una línea base de aproximación entre los interlocutores de un tema, especialmente nuevo como el Modelo Educativo Crítico con Enfoque de Competencias de la Universidad Cooperativa de Colombia. Este glosario es un punto de partida sencillo y determinante para comprender el Modelo, y más allá, para suscitar un interés por renovar la calidad de la comunicación educativa y académica en torno a definiciones formales, sentidos precisos, connotaciones intencionales, códigos clave... Por sus dos formas de leerlo, también es una estrategia para ensayar secuencias y combinaciones de definiciones que, sin ánimo lexicográfico determinístico, propongan sentidos nuevos, al mismo tiempo que flexibles y precisos.

\section{Palabras clave}

Competencias, glosario, Modelo Educativo Crítico con Enfoque de Competencias, polisemia. 


\title{
TABLA DE CONTENIDOS
}

\author{
PRESENTACIÓN 9
}

METODOLOGÍA 11

ÍNDICE ALFABÉTICO DEL GLOSARIO 12

OBSERVATORIO PARA LA GESTIÓN DE CONOCIMIENTO 16

CONCLUSIONES 43

REFERENCIAS 44 


\section{PRESENTACIÓN}

\section{Apreciados profesores:}

El año pasado, el Observatorio para la Gestión de Conocimiento y Rizoma Nacional, una vez finalizadas las visitas programadas conjuntamente y realizadas con el apoyo del ıx Comité Líder Rizoma de las sedes, se dio a la tarea de sistematizar los aprendizajes alcanzados.

El documento Primera aproximación práctica a la rúbrica institucional permitió una aproximación clara a la experiencia de campo de los profesores frente al modelo educativo crítico de la Universidad. La conclusión fue que era imprescindible unificar un horizonte de sentido, conceptual, en lo que a nuestro modelo se refiere. Pero ¿qué significa un mismo horizonte? Significa llegar a un acuerdo entre lo que expresa una palabra y el modo como esta es interpretada por los interlocutores. Significa reducir la polisemia. Significa que podamos conversar frente al mismo objeto de saber y que cuando lo hagamos, estemos lo más cerca posible del mismo concepto. Significa autorreflexionar sobre nuestros prejuicios e interpretaciones subjetivas, que por ego o gusto queremos imponer y hacer prevalecer sobre la lógica, la ética, la estética de la gramática. Significa ajustar los códigos a la institucionalidad del modelo. Si el lenguaje nombra con los significados acordados, las prácticas producto de estos significados compartidos responderán mejor a lo que justo el término "modelo educativo" significa: una aproximación conjunta hacia el acto de educar y de educarnos.

Fue así como pensamos en un glosario: "Del latín glossarium, es un catálogo de palabras de una misma disciplina o de un campo de estudio, que aparecen 
definidas, explicadas o comentadas. También se trata de un catálogo de palabras desusadas o del conjunto de comentarios [...]".

En ese sentido, su construcción ha sido, por un lado, con base en el libro del doctor Manuel Unigarro como referente clave; y por otro, con base en la práctica y conversación con los profesores, en las sedes y en las comunidades Rizoma, que nos han indicado qué conceptos son más usados y cuáles tienen mayor polisemia en el discurso corriente de la cotidianidad académica.

Y más allá de ser un catálogo, queremos que se convierta en un dispositivo para la gestión de conocimiento, continuando con la dinámica de plantear preguntas sobre la implementación del modelo y ensayar una secuencia de definiciones que propongan una respuesta, tal como aparece en el ejemplo. Como la palabra está viva en la lengua por su relación con la práctica, es preciso registrar sus ajustes, por eso el glosario que se presenta no es definitivo, sino autopoiético: se reensambla y se reproduce constantemente. Por ahora, esta versión 1.0 del glosario es un faro para iluminar lo que decimos y hacemos. Esperamos que remitan sus aportes de preguntas y secuencias de respuesta a Rizoma o al Observatorio. 


\section{METODOLOGÍA}

Este glosario puede ser leído de dos formas: la primera es secuencial de principio a fin en el orden en que ha sido escrito, lo cual le permitirá a quien se aproxima al modelo por primera vez una construcción de conocimiento de lo simple a lo complejo. La segunda forma es con base en una prioridad de preguntas específicas para quienes ya conocen el Modelo Educativo Crítico con Enfoque de Competencias de la Universidad Cooperativa de Colombia; preguntas que hallará en una tabla después del glosario. En ediciones posteriores, se incorporarán conceptos y preguntas nuevos que reporten los profesores que realicen rúbricas y las apliquen en clase; o que las calibren o avalen si hacen parte de las comisiones de curaduría.

Para facilitar el acceso y consulta de la forma aleatoria, se inserta a continuación un índice de conceptos en orden alfabético con los números ordinales.

El Observatorio para la Gestión de Conocimiento y Rizoma agradece a todos los profesores, empleados, Comités Líderes y colaboradores externos que hacen posible este trabajo de construcción. 


\section{ÍNDICE ALFABÉTICO DEL GLOSARIO}

\begin{tabular}{ll} 
Término / Concepto & Ordinal \\
\hline Abstracto ampliado (nivel de taxonomía solo) & 36 \\
\hline Alumno & 8 \\
\hline Anomia & 68 \\
\hline Autonomía como condición de éxito & 64 \\
\hline Bloom, B. & 80 \\
\hline Calibración de la rúbrica & 17 \\
\hline Calificación & 23 \\
\hline Calificación en el modelo educativo & 24 \\
\hline Chomsky, N.; Greimas, A. y Hymes, D. & 78 \\
\hline Ciencias crítico-sociales & 62 \\
\hline Ciencias empírico-analíticas & 60 \\
\hline Ciencias histórico-hermenéuticas & 61 \\
\hline Componente actitudinal & 44 \\
\hline Componente cognitivo & 43 \\
\hline Componente destreza & 45 \\
\hline
\end{tabular}




\begin{tabular}{|c|c|}
\hline Término / Concepto & Ordinal \\
\hline Contexto & 7 \\
\hline Curaduría de la rúbrica & 15 \\
\hline Curso & 13 \\
\hline Didáctica & 50 \\
\hline Educación personalizada & 42 \\
\hline Elemento de competencia & 10 \\
\hline Elemento de competencia HACER & 26 \\
\hline Elemento de competencia SABER & 25 \\
\hline Elemento de competencia SER & 27 \\
\hline Escala de complejidad en el nivel solo & 37 \\
\hline Estado de desarrollo de la competencia & 9 \\
\hline Estética como discurso dominante & 48 \\
\hline Ética como discurso dominante & 47 \\
\hline Evaluación & 18 \\
\hline Evidencia & 38 \\
\hline Habermas, J. & 49 \\
\hline Habla & 56 \\
\hline Heidegger, M. & 77 \\
\hline Husserl, E. & 76 \\
\hline Identidad personal & 70 \\
\hline Idioma & 53 \\
\hline Indicador & 19 \\
\hline Indicador de estado de desarrollo & 20 \\
\hline
\end{tabular}




\section{Término / Concepto}

Ordinal

\begin{tabular}{|c|c|}
\hline Institucionalidad de la rúbrica & 52 \\
\hline Institucionalidad del modelo & 51 \\
\hline Interdisciplinariedad & 75 \\
\hline Interés emancipatorio & 74 \\
\hline Interés práctico & 73 \\
\hline Interés técnico & 72 \\
\hline Lengua & 55 \\
\hline Lenguaje & 54 \\
\hline Lógica como discurso dominante & 46 \\
\hline Manual de aplicación de la rúbrica & 16 \\
\hline Mapa de competencias & 11 \\
\hline Matriz institucional de verbos & 22 \\
\hline Modelo & 1 \\
\hline Modelo educativo & 2 \\
\hline Modelo educativo crítico & 3 \\
\hline Modelo Educativo Crítico con Enfoque de Competencias & 4 \\
\hline Multiestructural (nivel de taxonomía solo) & 34 \\
\hline Mundo intersubjetivo & 41 \\
\hline Mundo natural & 39 \\
\hline Mundo subjetivo & 40 \\
\hline Pedagogía crítica & 6 \\
\hline Pérdida de sentido & 66 \\
\hline Plan de estudios & 12 \\
\hline
\end{tabular}




\begin{tabular}{l|l} 
Término / Concepto & Ordinal \\
\hline Pragmática & 30 \\
\hline Pragmática como fundamento lingüístico & 59 \\
\hline Psicopatología & 67 \\
\hline Racionalidad como condición de éxito & 63 \\
\hline Relacional (nivel de taxonomía solo) & 35 \\
\hline Relaciones personales reguladas & 71 \\
\hline Rúbrica & 14 \\
\hline Saber válido & 69 \\
\hline Secuencia progresiva de verbos & 21 \\
\hline Semántica & 29 \\
\hline Semántica como fundamento lingüístico & 58 \\
\hline Sintaxis & 28 \\
\hline Sintaxis como fundamento lingüístico & 57 \\
\hline Solidaridad como condición de éxito & 65 \\
\hline Taxonomía & 31 \\
\hline Taxonomía solo (Biggs y Collis, 1982) & 33 \\
\hline Teoría crítica & 79 \\
\hline Uniestructural (nivel de taxonomía solo) & 32 \\
\hline Van Dijk, T. & 37 \\
\hline & 39 \\
\hline
\end{tabular}

Nota. Elaboración propia del Observatorio para la Gestión de Conocimiento, 2019. 


\section{OBSERVATORIO PARA LA GESTIÓN DE CONOCIMIENTO}

Tabla 1. 80 campos conceptuales citados y comentados para disminuir la ambigüedad y hablar con propiedad sobre el Modelo Educativo Crítico con Enfoque de Competencias y la rúbrica

\begin{tabular}{l|l}
$\begin{array}{l}\text { Término / } \\
\text { Concepto }\end{array}$ & Significado / Interpretación en el modelo \\
& $\begin{array}{l}\text { "Del it. modello. 1. m. Arquetipo o punto de referencia para imi- } \\
\text { tarlo o reproducirlo. 3. m. Representación en pequeño de alguna } \\
\text { cosa. 4. m. Esquema teórico, generalmente en forma matemáti- } \\
\text { ca, de un sistema o de una realidad compleja, como la evolución } \\
\text { económica de un país, que se elabora para facilitar su compren- } \\
\text { 1. Modelo y el estudio de su comportamiento" (RAE, 2014). }\end{array}$ \\
\hline $\begin{array}{l}\text { 2. Modelo } \\
\text { educativo }\end{array}$ & $\begin{array}{l}\text { Esquema conceptual que articula teorías, postulados o criterios } \\
\text { de forma intencional, entre muchas posibles con el fin de ilus- } \\
\text { trar una manera particular de aproximarse al acto de educar. }\end{array}$ \\
\hline $\begin{array}{l}\text { Modelo educativo fundamentado en la convergencia de campos } \\
\text { conceptuales, teorías y postulados que procuran en el alumno } \\
\text { el fortalecimiento del criterio de realidad, la validez del cuestio- } \\
\text { namiento racional de los fenómenos y la recuperación de pensa- } \\
\text { miento autónomo, como base de construcción de conocimiento, } \\
\text { en todos los campos, áreas y sectores. }\end{array}$ \\
\hline
\end{tabular}


Término /

Concepto

4. Modelo Educativo Crítico con Enfoque de Competencias

\begin{tabular}{|c|c|}
\hline 5. Teoría crítica & $\begin{array}{l}\text { "La Teoría crítica tiene como núcleo central el mundo de la vida, } \\
\text { desarrollado por Jürgen Habermas y que se convierte en el mar- } \\
\text { co epistemológico del modelo. De allí se pasa a la Pedagogía } \\
\text { crítica y a la manera como se concibe la educación que se con- } \\
\text { creta en el currículo" (Unigarro, 2017, p. 12). }\end{array}$ \\
\hline & $\begin{array}{l}\text { "La Pedagogía crítica es la manera como se concreta en lo edu- } \\
\text { cativo el ideal de la Teoría crítica de educar para el Mundo de la } \\
\text { vida" (Unigarro, 2017, p. 29). }\end{array}$ \\
\hline $\begin{array}{l}\text { 6. Pedagogía } \\
\text { crítica }\end{array}$ & $\begin{array}{l}\text { "Con la fuerte crítica que Husserl (2008) hace en } 1936 \text { al positi- } \\
\text { vismo y con su propuesta de la fenomenología que va a conti- } \\
\text { nuar Habermas (1985), consistente en buscar la recuperación de } \\
\text { la consciencia del sujeto, del sentido del mundo de la vida, surge } \\
\text { otra mirada hacia la educación: la Pedagogía crítica" (Unigarro, } \\
\text { 2017, p. 30). }\end{array}$ \\
\hline 7. Contexto & $\begin{array}{l}\text { "Toda esta articulación armónica que se ha venido presentando, } \\
\text { esta tríada de ser-saber-hacer opera, para que sea competencia, } \\
\text { siempre en contextos concretos. El contexto hace referencia a un } \\
\text { entorno físico, cultural, político en el que se considera un hecho. } \\
\text { Pero el contexto no es algo externo al sujeto. El contexto, ese } \\
\text { entorno en el que las cosas suceden, resulta siendo una cons- } \\
\text { trucción intersubjetiva a partir de los conocimientos, las con- } \\
\text { vicciones y las valoraciones de los sujetos. Un mismo entorno } \\
\text { puede ser considerado de diversas maneras por individuos dife- } \\
\text { rentes. En tanto se comunican y van acercándose en la compren- } \\
\text { sión, van estructurando un determinado contexto. Por ello los } \\
\text { contextos no son estáticos; son dinámicos en tanto los sujetos } \\
\text { los van dotando constantemente de nuevos sentidos. Son cons- } \\
\text { truidos y reconstruidos en el momento por cada participante en } \\
\text { un evento, y cambian con cada cambio en la interpretación de la } \\
\text { situación (Van Dijk, 1980)" (Unigarro, 2017, pp. } 54 \text { y 56). }\end{array}$ \\
\hline
\end{tabular}

\section{Significado / Interpretación en el modelo}

Así se denomina el modelo educativo de la Universidad Cooperativa de Colombia, fundamentado en la teoría crítica de los filósofos de la escuela de Frankfurt, quienes procuran ejercer la filosofía sin vincularse a una ideología, conservando un pensamiento con criterio de realidad y emancipación.

"La Teoría crítica tiene como núcleo central el mundo de la vida, desarrollado por Jürgen Habermas y que se convierte en el marcrítica y a la manera como se concibe la educación que se concativo el ideal de la Teoria critica de educar para el Mundo de la vismo y con su propuesta de la fenomenología que va a continuar Habermas (1985), consistente en buscar la recuperación de la consciencia del sujeto, del sentido del mundo de la vida, surge otra mirada hacia la educación: la Pedagogía crítica" (Unigarro,

"Toda esta articulación armónica que se ha venido presentando, esta tríada de ser-saber-hacer opera, para que sea competencia, siempre en contextos concretos. El contexto hace referencia a un entorno físico, cultural, político en el que se considera un hecho. Pero el contexto no es algo externo al sujeto. El contexto, ese entorno en el que las cosas suceden, resulta siendo una construcción intersubjetiva a partir de los conocimientos, las conpuede ser considerado de diversas maneras por individuos diferentes. En tanto se comunican y van acercándose en la comprencontextos no son estáticos; son dinamicos en tanto los sujetos los van dotando constantemente de nuevos sentidos. Son construidos y reconstruidos en el momento por cada participante en un evento, y cambian con cada cambio en la interpretación de la 
Término /

Concepto

\section{Significado / Interpretación en el modelo}

"Si afirmamos que la competencia solamente se da en contexto, y entendemos contexto en el sentido del párrafo anterior, decimos entonces que la competencia lo es en tanto se va adaptando a la sucesión de configuraciones y reconfiguraciones que van haciendo que el contexto cambie continuamente. Si el contexto no es estático, tampoco la competencia puede serlo. En este orden de ideas, si los contextos se van configurando continuamente a partir de la interacción, así también deberán reconfigurarse las competencias para responder a la dinámica de los contextos" (Unigarro, 2017, p. 56).

"El centro del proceso educativo no está ni en el profesor, ni en el alumno; el centro del proceso educativo está, justamente, en la relación que se entabla entre ellos dos. No hay profesor sin alumnos, son estos quienes le dan estatuto de existencia al profesor; y viceversa, no se puede ser alumno si no existe un profe8. Alumno sor" (Unigarro, 2017, p. 98).

En el modelo educativo se habla de alumnos antes que de estudiantes, porque el concepto "alumno" implica la existencia de un proceso institucionalizado, es decir, formal, en que se entiende la relación con un profesor, una meta y un aprendizaje acompañado.

Cada uno de los doce niveles de dominio, en cada uno de los tres elementos de competencia: ser, saber y hacer, identificado con un verbo, concatenados en forma secuencial progresiva

9. Estado de desarrollo de la y creciente en complejidad, cuyo dominio y alcance lo da el indicador.

competencia

El estado de desarrollo de una competencia, de un alumno, determina no solamente a qué distancia está de ser competente, sino también si ya superó el estándar y comienza a ser excepcional.

Cada uno de los tres conceptos axiológicos del Modelo Educati-

10. Elemento de vo Crítico con Enfoque de Competencias ser, saber, hacer. Algucompetencia nos autores, como Manfred Max Neef en la teoría de desarrollo a escala humana, les llaman categorías existenciales. 


\begin{tabular}{|c|c|}
\hline $\begin{array}{l}\text { Término / } \\
\text { Concepto }\end{array}$ & Significado / Interpretación en el modelo \\
\hline $\begin{array}{l}\text { 11. Mapa de } \\
\text { competencias }\end{array}$ & $\begin{array}{l}\text { "Cuando se tienen todas las competencias de un programa } \\
\text { cualquiera, de pregrado o de posgrado, estructuradas con sus } \\
\text { elementos de competencia respectivos, se tiene el mapa de } \\
\text { competencias. Este mapa es lo primero que se debe elaborar } \\
\text { cuando se diseña un programa, una carrera. Y solamente des- } \\
\text { pués de tener ese mapa completamente terminado, se procede } \\
\text { a definir cuáles son los cursos que enseñarán esas competencias } \\
\text { y esos elementos, y allí entonces se arma el plan de estudios" } \\
\text { (Unigarro, 2017, pp. 76-77). }\end{array}$ \\
\hline
\end{tabular}

\begin{tabular}{ll}
\hline "El plan de estudios se refiere a la organización y secuencia de \\
cursos y actividades académicas que conducen a la consecu- \\
ción del título que busca el alumno. Y eso es solo uno de varios \\
espacios para su formación. El plan de estudios es, tal vez, la \\
columna vertebral del currículo en tanto eje y soporte de toda \\
12. Plan de \\
estudios \\
currículo. Quienes desempeñan labores de tipo administrativo, \\
secretaría, pagaduría, el personal de aseo, de mantenimiento, \\
las cafeterías, los espacios para la recreación y el deporte, todo \\
ello es también parte constitutiva del currículo" (Unigarro, \\
2017, p. 38). \\
"Los planes de estudio en este enfoque deben estar conforma- \\
dos por cursos, no por asignaturas. La palabra curso también es \\
polisémica, en el diccionario de la RAE tiene 13 acepciones. En la \\
presente propuesta se entiende curso como el abordaje de una \\
determinada competencia, o de algún elemento de competen- \\
cia, en un periodo determinado de tiempo. En efecto, existen \\
competencias cuya complejidad permite que se desarrollen \\
completamente en un solo curso; pero existen otras que requie- \\
ren de varios cursos para desarrollarse plenamente" (Unigarro, \\
2017, p. 77). \\
En otros modelos se les nombra asignaturas. En el presente \\
modelo se afirma que cada curso desarrollará máximo una com- \\
petencia. Con esto no se desconoce que en cualquier curso, de \\
cualquier modelo o enfoque, los alumnos siempre logran más \\
de lo pretendido; logran hasta cuestiones no pretendidas.
\end{tabular}


Término /

Concepto

\section{Significado / Interpretación en el modelo}

"Al limitar a una sola competencia por curso, se garantiza la concentración de profesores y alumnos en una sola dirección a fin de garantizar esa construcción. También esta limitación parte de un sano principio de realidad, y es que las personas normalmente somos limitadas en el número de competencias que podemos desarrollar. No es posible ser competente en todo" (Unigarro, 2017, p. 77).

"La rúbrica es una matriz de valoración cuya principal finalidad es mostrar cuáles son los criterios para verificar la tarea que se quiere evaluar. Con ella tanto alumnos como profesores tienen claro qué desempeños son aceptables para alcanzar la promoción o aprobación" (Unigarro, 2017, p. 87).

Desde la gestión de conocimiento, la rúbrica es un dispositivo realizado con técnica, intelecto y talento, para medir doce posibles estados de desarrollo de una competencia, con base en la estructura que el modelo educativo determina a partir de la 14. Rúbrica combinatoria de cuatro niveles de la taxonomía solo y tres escalas de dificultad secuencial y progresiva.

Las rúbricas del modelo solo se realizarán una vez, se calibrarán y afinarán durante unos semestres, para luego dotarlas de actividades didácticas y momentos evaluativos, levantados por sus profesores, y disponerlas en un Sistema de Gestión de Conocimiento. Cuando lleguen nuevos profesores a enseñar a desarrollar esas competencias, utilizarán las mismas rúbricas y podrán conocer cómo ha sido el desempeño de esos instrumentos, didácticos y evaluativos.

Proceso aplicado por expertos autorizados en la disciplina respectiva, para verificar tres cosas, al momento de realizar una rúbrica por primera vez: 1) que el verbo 7 de cada elemento de

15. Curaduría competencia, es decir, el verbo del nivel Relacional 1, declara de la rúbrica un estado de desarrollo de la competencia, claro, posible y conveniente para la calidad educativa institucional; 2) que las acepciones son formales y están debidamente citadas; 3) que la secuencia, enfoque, alcance y dominio de los indicadores son los adecuados. 
Término /

Concepto

\section{Significado / Interpretación en el modelo}

Cuando la rúbrica pasa el proceso de curaduría, como toda obra del intelecto y el talento, se registra y se acoge institucionalmente como la única rúbrica institucional para desarrollar esa competencia. El registro consiste en otorgarle un ID en el cual se condensa toda la metainformación, que soporta su realización. Este orden es parte de la gestión de conocimiento que documenta el proceso.

\begin{tabular}{|c|c|}
\hline $\begin{array}{l}\text { 16. Manual de } \\
\text { aplicación de } \\
\text { la rúbrica }\end{array}$ & $\begin{array}{l}\text { Es el instructivo de trabajo con la rúbrica en la clase, en el día a } \\
\text { día de trabajo entre el profesor y el alumno. Contiene una des- } \\
\text { cripción detallada de los alcances de cada estado de desarrollo. } \\
\text { El profesor deberá levantar una bitácora de desempeño de la } \\
\text { rúbrica, por cuanto es su instrumento de trabajo, a manera } \\
\text { de diario de campo, para comentar cómo es la relación di- } \\
\text { dáctica entre los alumnos y él en las comunidades Rizoma de } \\
\text { Aprendizaje. }\end{array}$ \\
\hline \multirow[t]{2}{*}{$\begin{array}{l}\text { 17. Calibración } \\
\text { de la rúbrica }\end{array}$} & $\begin{array}{l}\text { Mientras la curaduría se realiza por parte de expertos autoriza- } \\
\text { dos por la disciplina, y es de orden colegiado para la primera } \\
\text { rúbrica que proponen los profesores para una competencia, la } \\
\text { calibración de la rúbrica puede ocurrir todo el tiempo mientras } \\
\text { el profesor la utiliza en clase, pues él podrá reportar al final del } \\
\text { semestre cómo ha sido el desempeño de la rúbrica en ese perio- } \\
\text { do. Las rúbricas se diseñan, se realizan, se curan, se publican, se } \\
\text { aplican, se ajustan y vuelven a publicarse y aplicarse, hasta que } \\
\text { se logra una calidad excepcional. }\end{array}$ \\
\hline & $\begin{array}{l}\text { Una rúbrica se afina en su aplicación desde una perspectiva } \\
\text { didáctica únicamente en el salón de clase. Por eso los profesores } \\
\text { participan activamente en su perfeccionamiento, reportando } \\
\text { sus logros y dificultades; sugiriendo verbos más especializados y } \\
\text { pertinentes para un estado de desarrollo. }\end{array}$ \\
\hline 18. Evaluación & $\begin{array}{l}\text { Evaluar es "medir y comparar el grado de refinamiento de las } \\
\text { competencias, para: 1) construir sentido, es decir, orientar los } \\
\text { mundos posibles, vislumbrar nuevos contextos; 2) criticar y } \\
\text { discriminar, separando lo deseable de lo no deseable; 3) tomar } \\
\text { decisiones para corregir oportunamente; 4) acreditar" (Unigarro, } \\
\text { 2017, p. 86). }\end{array}$ \\
\hline
\end{tabular}


Término /

Concepto

\section{Significado / Interpretación en el modelo}

En este modelo, las competencias se evalúan con base en pruebas o momentos evaluativos que integren simultáneamente lo cognitivo, lo actitudinal y lo procedimental; por esa razón, una sola evaluación deberá dar cuenta del estado de desarrollo de cada uno de los tres elementos de la competencia, para lo cual se formulan de forma independiente y se les atribuye una secuencia progresiva de verbos. Se sugieren mínimo tres momentos evaluativos en el periodo: el primero antes de la cuarta semana para saber qué alumnos pasaron del uniestructural al multiestructural; un segundo momento evaluativo antes de la semana ocho para saber cuántos alumnos pasaron del multiestructural al relacional; un tercer momento entre las semanas 12 y 14 para saber qué alumnos no han logrado la competencia y dedicarse a ellos de forma especial, así como para ayudar a que quienes ya la lograron la puedan llevar a niveles excepcionales. Como en estos momentos evaluativos no hay calificación, no hay acumulación, ni pérdida; solo puede haber monitoreo permanente sobre los estados de desarrollo de la competencia, mucha conversación, argumentación, acompañamiento, sugerencia, trabajo, dedicación, entrenamiento, por lo menos hasta que alcance la competencia y pueda avanzar más si es posible y deseable.

"Los indicadores se refieren a las acciones que ejecutará el alumno y con ellas se podrá observar qué tanta apropiación del elemento existe. Un indicador bien formulado responde a la pregunta: ¿qué debe hacer el alumno para demostrarle al profesor su dominio sobre el elemento de competencia? Un elemento de competencia puede requerir, para ser demostrado, más de un indicador. Todo depende de la complejidad del elemento y también de lo amplio que pueda ser el indicador, que lleva a 19. Indicador mostrar los resultados del desempeño del alumno. De esto se desprende, entre otras cosas, que la evaluación de competencias requiera más ejecuciones y menos pruebas de papel y lápiz" (Unigarro 2017, p. 78).

"La relación entre el indicador y la evidencia se puede establecer interponiendo entre ellos la palabra 'mediante'. Así, por ejemplo, retomando del cuadro anterior, se podría decir: 'Justifica su propiarutina de calentamiento y entrenamiento mediante un texto escrito"' (Unigarro, 2017, p. 80). 
Término /

Concepto

20. Indicador de estado de desarrollo

\section{Significado / Interpretación en el modelo}

"Lo que se utiliza para mostrar el indicador, lo que se entrega para hacerlo observable, es la evidencia. La mejor evidencia muestra, sin equívocos, el indicador que se está buscando. Un indicador puede requerir una sola evidencia; pero, y según su complejidad, un indicador también puede requerir varias. También es posible que una misma evidencia pueda servir para mostrar más de un indicador" (Unigarro, 2017, p. 79).

"Cuando se diseña la competencia, es fundamental mostrar cuál o cuáles son los problemas que ella resuelve o contribuye a resolver. Ya se había dicho antes que muchos problemas requieren para su resolución más de una competencia. La pertinencia de una competencia viene dada por la utilidad que tenga para resolver problemas concretos. Muchas de las críticas a la educación tienen que ver, justamente, con la impertinencia de lo que se enseña. Por ello, es fundamental mostrarle a un alumno que lo que se pretende enseñar tiene sentido, y que ese sentido se refiere a circunstancias concretas de su espacio próximo operable" (Unigarro, 2017, p. 80).

Es una cadena de doce verbos legítimos del idioma español, organizados desde el más sencillo hasta el más complejo, en función del nivel de complejidad de la capacidad del alumno frente al alcance de una competencia. Los doce verbos están clasificados en grupos de tres, para cada uno de los cuatro niveles de la taxonomía solo de Biggs y Collis (1982) ${ }^{1}$.

21. Secuencia progresiva Una rúbrica se realiza con tres secuencias progresivas de verbos, una para cada elemento de competencia: SER, SABER Y HACER. Los verbos necesarios para armar la secuencia progresiva se toman de la matriz institucional de verbos. Si un estado de desarrollo de una competencia puede describirse mejor con un verbo que no se encuentra en la matriz institucional, puede sugerirse su incorporación en la Bitácora de desempeño de la rúbrica al final del periodo, junto con la acepción de uso tomada de una fuente formal.

1 La taxonomía solo fue publicada en Biggs y Collis (1982). 
Término /

Concepto

\section{Significado / Interpretación en el modelo}

La elección del verbo siete, en la posición relacional de escala 1, es clave para calibrar el alcance y la pertinencia de la competencia; ya no puede ser muy exigente para no frustrar los esfuerzos de los alumnos, ni muy laxo para no deteriorar la calidad de competente del profesional.

Es la retícula en la que se presentan clasificados los 73 verbos disponibles de la versión 2.0 de la matriz de verbos disponibles. Se aprecian hasta cuatro o cinco verbos en algunos estados de desarrollo o casillas, porque se trata de un conjunto de verbos disponibles para la realización de rúbricas. La variedad de verbos responde a la variedad de campos de conocimiento, mientras se conserva la secuencia progresiva.

Esta matriz institucional de verbos se actualiza cada vez que, luego del proceso de curaduría, en una rúbrica surge un verbo que no estaba disponible y al cual se le atribuye una acepción formal, pertinente y necesaria.

Los verbos están clasificados en esta matriz, con tres atributos:

22. Matriz institucional de verbos 1) pertenecen a un único elemento de competencia (SER, SABER Y HACER) y no se pueden cambiar en este modelo; 2) pertenecen a una escala de complejidad (1, 3 y 5), la cual puede variar al momento de diseñar una secuencia cuando se realiza una rúbrica; y 3) cada verbo comporta su valor taxonómico solo, siendo uniestructural, multiestructural, relacional o abstracto, en cualquier lugar donde se inserte al realizar una rúbrica. En una secuencia progresiva de doce verbos siempre estarán primero los verbos uniestructurales que se elijan, luego los multiestructurales, le seguirán los verbos de valor taxonómico relacional y al final estarán los verbos de orden abstracto ampliado. Si el nivel de exigencia en calidad de comprensión es muy alto, es muy probable que la secuencia se realice sin verbos uniestructurales, porque los multiestructurales los desplazan. Todo depende de la calidad que se quiere lograr en la triada: conocimiento, habilidad y actitud.

Expresión numérica que pretende expresar un referente de cali-

23. Calificación dad del conocimiento desarrollado en un proceso de aprendizaje, el cual casi siempre se aprecia como el logro del alumno y no como el desempeño del profesor. 
Término /

Concepto

\section{Significado / Interpretación en el modelo}

Generalmente, la calificación está desarticulada de los procesos de enseñanza, aprendizaje, evaluación y calificación. Se asume por defecto que el profesor determina de forma subjetiva el valor que merece el logro del alumno, para lo cual dispone de 50 posibilidades, dadas por cinco enteros y sus decimales.

En el Modelo Educativo Crítico con Enfoque de Competencias, se tiene una tabla con solo doce números, uno para cada estado en la secuencia de estados de desarrollo de la competencia, y cada una de las doce casillas corresponde a un valor aritmético: $0,5-1,0-1,5-1,8-2,3-2,8-3,0-3,5-4,0-4,3-5,0$. Los valores surgen de un algoritmo aritmético diseñado con base en tres atributos de manera ponderada: posición, proximidad y complejidad.

Técnicamente hablando, no se califican alumnos con la rúbrica, sino que se evalúa el estado de desarrollo de su competencia. La

24. Calificación en el modelo educativo calificación surge al final del periodo como atribución directa, que corresponde al valor que tiene cada casilla, la cual corresponde a su vez al estado de desarrollo en cada uno de los tres elementos que logra el alumno. Este proceso no da lugar a subjetividades, pues el estado de desarrollo de la competencia está soportado en evidencias cualitativas, según el indicador que corresponda a la posición. Si otro profesor verifica la calidad de las evidencias, en contraste con la rúbrica, llegará a la misma conclusión y se obtendrá la misma posición y número.

Un alumno debe alcanzar, mínimo, el nivel 7 del estado de desarrollo de su competencia en cada uno de los tres elementos (HACER, SABER, SER) para que pueda pasar el curso.

"En la competencia, el SABER HACER al SER. En efecto, los conocimientos construidos de alguna manera van modificando a la persona. Por eso, se observan ciertas transformaciones en los alumnos una vez que empiezan a transitar los caminos de la educación universitaria. Quienes estudian Medicina, por ejemplo, van asumiendo actitudes y comportamientos que los diferencian de quienes estudian Ingeniería, Derecho o Literatura. Cuando el saber no hace al ser, no hay competencia. Significa que la persona no ha sido permeada por el saber. Significa que lo que sabe no es parte constitutiva de su ser; $y$ en ese sentido ese saber es solamente un accesorio. La competencia modifica, construye el ser del competente" (Unigarro, 2017, p. 53). 
Término /

Concepto

\section{Significado / Interpretación en el modelo}

"En la competencia, el SABER ES HACER. Todo conocimiento debe ser ejecutado de alguna manera para que sea reconocido como tal. Esto va a ser determinante, por ejemplo, a la hora de evaluar la competencia; porque ello solamente se logra a partir de la ejecución. De esta manera, en un currículo con enfoque de competencias, la pregunta ‘qué sabes?' no se puede separar de '¿qué haces?', porque lo que sabes es, definitivamente, lo que haces. Cuando el saber no es hacer, no existe competencia. Existe solamente teoría, conocimiento vacío o un mero divertimento intelectual. El conocimiento enciclopédico no es el propio del competente; y la evaluación de una competencia no se podrá hacer solamente verificando el saber" (Unigarro, 2017, pp. 53-54).

La persona que no construye el saber no es competente. Cuando no se construye el saber, lo único que existe es un acto de consumir ideas que vienen dadas por otros; de escuchar las palabras de otros sin pronunciar las propias. Renunciar a construir el saber es renunciar a ser protagonista.

En la competencia, el HACER ES SABER, en el sentido de que toda ejecución tiene su fundamento en el conocimiento.

Toda acción competente deriva de lo que su ejecutor conoce. En el mismo sentido que en la relación anterior, esta será una de las claves para la evaluación. Así la pregunta ¿qué haces? no puede estar separada de ¿qué sabes?, porque lo que haces es lo que sabes" (Unigarro, 2017, p. 54).

"En las situaciones en las que no sabe hacer, es decir, en las situaciones de incompetencia, la persona será un ser fundamentalmente heterónomo. Y esto es así en muchos aspectos de la vida cotidiana. En tanto uno no puede ser competente en todo, es incompetente en muchos asuntos; por ello termina dependiendo de otros. Tenemos entonces que a mayor competencia, mayor grado de autonomía" (Unigarro, 2017, p. 52).

"El competente es un SER que SABE HACER. Tal vez esta es la relación que con mayor frecuencia se establece y se muestra en muchas

27. Elemento de definiciones de competencia. Tiene que ver con la persona capaz competencia SER de llevar a la práctica sus conocimientos” (Unigarro, 2017, p. 51).

"Esa conjunción de conocimientos (sintaxis), actitudes (semántica) y habilidades (pragmática) que se da en la competencia es lo 
Término /

Concepto

\section{Significado / Interpretación en el modelo}

que concreta la posibilidad de articular el saber, el ser y el hacer. Las relaciones que se establecen a partir de esta tríada nos muestran la complejidad que existe en la competencia" (Unigarro, 2017, p. 51).

"El competente es un SER que HACE SABER. En este sentido, desarrollar alguna competencia pasa necesariamente por la construcción del saber. Para ser competente, es fundamental elaborar el saber que más adelante se llevará a la práctica" (Unigarro, 2017, p. 52).

"La manera como los códigos se van articulando en cada profesión y van configurando su marco teórico, su discurso propio, se llama sintaxis. Lo sintáctico se relaciona directamente con la dimensión cognitiva que consiste en apropiar unos códigos del campo de quien los estudia. Greimas (1973) complejiza el planteamiento de Chomsky al introducir el asunto de la manera como las personas van asignando significados distintos y cómo,

28. Sintaxis entonces, los códigos no van en la misma dirección siempre. Por ello deben hacer un ejercicio de argumentar para sustentar los significados que van construyendo. (...) Hymes (1996) insiste en que la sintaxis y la semántica no son el punto de llegada de la competencia. Además de tener unos códigos y unas comunidades semánticas, es indispensable pasar al campo del uso. Se refiere el autor a la pragmática y está en directa relación con la dimensión procedimental de la competencia, con la esfera del hacer" (Unigarro, 2017, p. pp. 51-52).

El estudio del sentido de los símbolos en un contexto es el objeto de la semántica; y el modelo educativo crítico tiene como fundamento lingüístico el SER por medio de la semántica, cuyo discurso clave es la estética y cuyo componente es la actitud. Por eso, el alumno compromete su visión subjetiva de los fenó-

29. Semántica menos cognitivos en función del significado y de su uso. La idea fundamental aquí es la interpretación; y el alumno no interpreta tanto por lo que sabe o hace, sino por lo que Es.

Mientras la sintaxis se ocupa de las reglas correctas de construcción, la semántica se ocupa del sentido entendible de esas expresiones. En una línea de tiempo, la semántica, por medio 
Término /

Concepto

\section{Significado / Interpretación en el modelo}

de la lexicografía, puede analizar cómo cambian los significados de un término para crear glosarios y diccionarios en función de nuevo conocimiento y uso.

El fundamento lingüístico del HACER como elemento de competencia es la pragmática, su componente es la habilidad, y su discurso clave es la ética. La pragmática le permite al alumno elegir el sentido preciso para el contexto adecuado según el uso, de tal forma que se reduzca la ambigüedad y se incremente el conocimiento.

30. Pragmática

La ética se ha tratado de enseñar, tradicionalmente, como un acondicionamiento de la actitud, por eso existen muy buenas personas que son pésimos profesionales. En este modelo, la ética no se enseña y menos desde el ser; la ética se practica en el hacer. Porque la ética no es un asunto de la vida privada, es una proyección estética del sujeto, hacia el ámbito público, a través del procedimiento. Solo cuando lo hacemos todo bien, somos éticos.

El término "taxonomía” se deriva del griego taxis, "ordenamiento", y nomos, "norma"' o "regla"; en su sentido más general, es la ciencia de la clasificación (Wikipedia, s. f. a).

31. Taxonomía

El valor agregado que implica para el modelo acoger una taxonomía es la rigurosidad científica del método, la precisión de las categorías.

John Burville Biggs nació en Tasmania, Australia, en 1934. Terminó Psicología en la Universidad de Tasmania (1957); en 1958 en Inglaterra inició estudios de posgrado en Educación en la escuela de Luton, y comenzó a investigar métodos de enseñanza y aritmética en la Fundación Nacional para la Investigación Educativa. En 1963, en el Birkbeck College de la Universidad de Londres,

32. Taxonomía solo (Biggs y Collis, 1982) inició sus trabajos sobre la relación entre la teoría psicológica y la práctica educativa. Trabajó en varias universidades: Universidad de Nueva Inglaterra, Universidad de Monash y Universidad de Newcastle en Australia, y Universidad de Hong Kong.

En 1982, publicó su teoría de la estructura del aprendizaje observado, conocido como taxonomía solo, junto con Kevin Collis, en su obra Evaluating the Quality of Learning: The solo Taxonomy, traducida a varios idiomas, incluido el chino. 
Término /

Concepto

\section{Significado / Interpretación en el modelo}

Esta teoría fue diseñada para realizar análisis sobre la estructura de la complejidad del aprendizaje y para facilitar a los profesores universitarios cómo enseñar de forma más eficiente y progresiva. En la Universidad Cooperativa de Colombia, esta teoría es la línea de partida del modelo educativo, combinándola con otras seis teorías, como la teoría crítica, la teoría del mundo de la vida, la teoría del lenguaje y la teoría de la fenomenología, entre otras. En enero de 2019, la Universidad invitó al doctor Biggs para que conociera el modelo, pero por motivos de salud declinó la invitación.
33. Uniestructural (nivel de taxonomía solo)

"En este nivel se identifica algún aspecto del objeto de aprendizaje; y no siempre es el aspecto más relevante. Hay acciones fragmentadas y prácticamente el alumno no establece relaciones en el contexto del objeto de aprendizaje. Hay únicamente pequeñas aproximaciones. Aquí no hay incompetencia, hay una competencia en ciernes. Pero es un nivel de competencia que no satisface los requerimientos de la sociedad hacia a un profesional” (Unigarro, 2017, p. 88).

Un grupo de alumnos que se encuentren en este nivel de complejidad de comprensión será lo que más atención requerirá por parte del profesor, pues se trata de realizar el proceso que inicia más lejos del nivel relacional, donde se alcanza la competencia, pues un alumno pasará necesariamente en forma consecutiva y secuencial al próximo nivel, en este caso al multiestructural.

"En este nivel, el alumno ya maneja varios elementos del objeto de aprendizaje. Sin embargo, no es capaz de armonizarlos o articularlos. Los identifica, los usa, pero cada uno de manera aislada. Así entonces las acciones son inconexas, sin ninguna relación. En este nivel se ha avanzado un poco más frente al

34. Multiestructural (nivel de taxonomía solo) anterior, pero aún no es el nivel que una persona debe alcanzar para enfrentar los retos de su ejercicio profesional" (Unigarro, 2017, p. 88).

Un grupo de alumnos que se encuentren en este nivel de complejidad de comprensión está muy cerca del nivel relacional, donde se alcanza la competencia; por lo tanto, es muy probable que puedan participar en actividades en las que ayuden a los del nivel uniestructural y juntos pasen al nivel relacional. 
Término /

Concepto

35. Relacional (nivel taxonomía soto)

\section{Significado / Interpretación en el modelo}

"En este nivel ya se alcanza la comprensión amplia del objeto de aprendizaje. Se articulan todos los elementos que lo conforman y se alcanza la dimensión de complejidad de ese objeto. Las acciones resultantes tienen sentido y son eficaces. Aquí ya se tiene un nivel de competencia importante y es lo mínimo que se espera de un profesional" (Unigarro, 2017, pp. 88-89).

Un grupo de alumnos que se encuentren en este nivel de complejidad de comprensión ya es competente. Por esta razón, las actividades que se diseñen para ellos estarán enfocadas a elevar su competencia a niveles de excelencia, y probablemente encauzarlos en actividades de investigación.

"En este nivel se logran generalizaciones de alta complejidad y se pueden formular hipótesis con los elementos que conforman el objeto de aprendizaje, ya relacionados y asumidos en su totalidad; y con otros objetos, los alumnos en este nivel logran establecer conexiones nuevas y crear mundos posibles. Evidentemente, los profesionales que logran este nivel son los que

36. Abstracto ampliado (nivel taxonomía solo) muestran desempeños sobresalientes" (Unigarro, 2017, p. 89).

Un grupo de alumnos que se encuentren en este nivel de complejidad de comprensión supera los estándares de la competencia. Será necesario que el profesor diseñe estrategias enfocadas a aplicar su conocimiento en actividades de investigación y proyección que desborden el límite del aula y traigan al grupo una perspectiva disruptiva de la competencia.

La escala de complejidad 1, 3 y 5 se creó con el propósito de ampliar a tres subniveles cada elemento de competencia en cada nivel solo. Estos subniveles funcionan ampliando la resolución, porque extendiendo la amplitud de observación y asignando allí estados de desarrollo intermedios, se puede calificar con mayor precisión.

En cada nivel solo, en la escala 1 se encuentran los verbos menos complejos; en la escala 3 se encuentran los medianamente complejos; y los verbos más complejos del nivel están en la escala 5. Por eso quien logre el estado de desarrollo de la escala 5 ya realiza los niveles anteriores, porque la secuencia progresiva es creciente en complejidad. 
Término /

Concepto

38. Evidencia

\section{Significado / Interpretación en el modelo}

Según el diccionario de la Real Academia Española (2014), “del lat. evidentia. 1. f. Certeza clara y manifiesta de la que no se puede dudar. 2. f. Prueba determinante en un proceso".

"Lo que se utiliza para mostrar el indicador, lo que se entrega para hacerlo observable, es la evidencia. La mejor evidencia muestra sin equívocos el indicador que se está buscando. Un indicador puede requerir una sola evidencia; pero, y según su complejidad, un indicador también puede requerir varias. También es posible que una misma evidencia pueda servir para mostrar más de un indicador" (Unigarro, 2017, p. 79).

"La vida del ser humano se desarrolla en varios ámbitos: el de la naturaleza, que es el espacio en donde todos nos movemos. En tanto tenemos cuerpo, no podemos sustraernos de su mecánica y somos afectados por ella; vivimos la dinámica que cualquier ser vivo vive. Este ámbito se denomina 'mundo objetivo'" (Unigarro, 2017, p. 16).

"Habermas (1985) plantea que hay tres tipos de racionalidad: la técnica, la hermenéutica y la emancipadora. La racionalidad técnica es la de las ciencias naturales, que parten de matematizar la realidad para garantizar la validez universal del conocimiento, al cual se llega mediante la investigación objetiva, libre de valores, neutral y comprobable. Esta racionalidad pretende que así como el mundo natural es objeto de leyes que se formulan con la investigación, también el mundo social ha de serlo, y con ello se pueden predecir los hechos sociales. Entonces, el resultado es un conocimiento fijo, inmóvil, acabado, que debe transmitirse. Resulta de esta racionalidad el conformismo y la pasividad. Con ello se pretende evitar todo juicio de valor, todo cuestionamiento. Se apaga la consciencia con el argumento de la integración y la armonía” (Unigarro, 2017, pp. 31-32).

"Conformado por las propias vivencias, por la particular manera de ser, de expresarse, de conocer; en otros términos, es la mismidad. Es el espacio de privacidad al que solamente se tiene acceso cuando la propia persona lo manifiesta. Al mundo subjetivo se accede desde la autonomía y mediante el lenguaje. Se asume el lenguaje como el conjunto de señales que se usan para dar a entender algo. La persona se muestra mediante él; 
Término /

Concepto

\section{Significado / Interpretación en el modelo}

solamente el lenguaje hace posible que una persona se diga, se manifieste. En el mismo sentido que afirmara Heidegger (2000), el ser se encarna en el lenguaje. Mediante él una persona puede relacionarse con los demás y, a partir de esa relación, fortalecer su identidad. Para manifestarse, para decirse claramente, el sujeto busca signos, símbolos y señales; de allí que el conocimiento que se construye en este mundo tenga un interés práctico" (Unigarro, 2017, pp. 18-19).

"Desde la perspectiva de la pedagogía crítica que aquí se asume, entendemos entonces que si la educación ha de preparar para el mundo de la vida, no puede quedarse solamente en la dimensión objetiva, en el discurso de la lógica, en la mirada de las ciencias naturales. Deberá esta educación abarcar también el mundo subjetivo y el intersubjetivo. Y en la armonización de esas tres esferas se encuentra la manera como se abordan las competencias en este texto. $Y$ desde esa misma perspectiva, se entiende que el discurso de las competencias puede ser aprovechado para diversos fines. De allí que deba asumirse críticamente a fin de evitar las desviaciones, la pérdida del sentido que queremos darle" (Unigarro, 2017, pp. 46-47).

"Constituido por las relaciones interpersonales legítimamente reguladas, es la confluencia de varios sujetos, de otros yo, de varias mismidades. En esa confluencia, cada uno de los que intervienen está en la búsqueda de ser más, de construirse como persona. A este mundo se ingresa a través de la interacción social y allí se descubre la auténtica contingencia del individuo: necesitar del otro. En efecto, aquí se entiende a plenitud que la única posibilidad de ser es a partir de ser con otros; que la

41. Mundo intersubjetivo subjetividad resulta de la construcción que se hace a partir del encuentro con otras subjetividades. Por eso el reconocimiento del otro tiene un interés emancipador.

La solidaridad, la adhesión a la causa de los otros, es la que hace posible vivir el mundo intersubjetivo. De allí que el discurso que prima en este mundo sea el ético y las ciencias que construyen el conocimiento propio de esta zona del mundo de la vida se denominan crítico-sociales. Con estos conocimientos, se obtienen unas relaciones interpersonales reguladas que favorecen la articulación entre los intereses individuales y los 


\begin{tabular}{l|l}
$\begin{array}{l}\text { Término / } \\
\text { Concepto }\end{array}$ & Significado / Interpretación en el modelo \\
& $\begin{array}{l}\text { colectivos. Con ello, cada persona puede desarrollarse como } \\
\text { tal sin que ese desarrollo suponga el estancamiento de otros. } \\
\text { La ausencia del conocimiento crítico-social genera la anomia" } \\
\text { (Unigarro, 2017, pp. 19-20). }\end{array}$ \\
\hline 42. Educación & $\begin{array}{l}\text { Es el tipo de educación que se diseña en función de las caracte- } \\
\text { rísticas de la persona. Para este modelo, y en términos técnicos, } \\
\text { pexisten solo cuatro tipos de personas, una por cada nivel de la } \\
\text { taxonomía. Por eso se afirma que un profesor solo tiene que } \\
\text { desarrollar actividades didácticas y evaluativas para cada grupo. }\end{array}$ \\
\hline $\begin{array}{l}\text { "Al saber le corresponde la dimensión lógica. Del griego logikée, } \\
\text { hace referencia al ejercicio de la razón para determinar el origen, } \\
\text { la extensión y el valor objetivo del conocimiento. Lo cognitivo } \\
\text { no puede desligarse de la lógica, aunque ella no lo contenga } \\
\text { todo. En la tradición educativa, lo que más se ha impulsado es el } \\
\text { discurso lógico. Por eso, la educación aparece tan centrada en el } \\
\text { conocimiento, en el saber puro. Desde la perspectiva del Mundo } \\
\text { de la vida, esta dimensión se desarrolla a partir de las ciencias } \\
\text { empírico-analíticas" (Unigarro, 2017, p. 58). }\end{array}$ \\
\hline
\end{tabular}

\begin{tabular}{ll}
\hline "Cualquier competencia tiene un componente actitudinal, es \\
decir, una zona en la cual la persona dice su palabra, expresa su \\
posición, da cuenta de sus adhesiones y de sus rechazos. Como \\
se planteó antes en el capítulo acerca del Mundo de la vida, la \\
persona utiliza el lenguaje para expresarse, para manifestarse. Y, \\
retomando a Heidegger (2000), el mejor lenguaje es el que tiene \\
que ver con las artes, con la poesía en tanto que es lenguaje que \\
parte de la armonía. Por ello este es el lugar de la estética" (Uni- \\
garro, 2017, p. 50). \\
"Lo actitudinal, que tiene que ver con la manera como el ser se \\
muestra, se dice, tiene su primerísimo vehículo en el lenguaje de \\
la estética. Desde la perspectiva del mundo de la vida, esta dimen- \\
sión se desarrolla a partir de las ciencias histórico-hermenéuticas. \\
En algunas propuestas educativas, se observa que el abordaje \\
de lo actitudinal se hace desde la ética. Y entonces se piensa que \\
hablar del ser se refiere a hablar de valores morales y de compor- \\
tamientos adecuados. La dimensión del ser es la dimensión de la \\
subjetividad. Si dejamos aquí la ética, entonces llevamos lo ético \\
a la esfera de lo subjetivo. Justamente, cuando la ética no pasa \\
de ser un asunto de la subjetividad, las sociedades encuentran
\end{tabular}


Término /

Concepto

\section{Significado / Interpretación en el modelo}

que es imposible construir tejido. Uno de los factores que impiden la construcción de tejido social es que la ética queda relegada a un asunto de la vida privada, de lo más íntimo del sujeto" (Unigarro, 2017, pp. 58-59).

La actitud en el modelo se evidencia a partir de la intencionalidad de interpretación y expresión del alumno frente a la trascendencia de la competencia; también se puede apreciar en el grado de compromiso, interés, recursividad y calidad que le otorga al alcance de su competencia.

Los alumnos entrenan, utilizan, hacen, realizan, elaboran, repiten una acción hasta lograr un estándar, ya sea introducir tubos

45. Componente destreza a un paciente asistido, compilar datos estructurando un informe manualmente, redactar un algoritmo y codificarlo, o medir, pesar y extraer, hasta que logren la destreza procedimental que les exige el modelo en la pragmática.

46. Lógica como discurso dominante

Aquello que la pedagogía crítica pretende cambiar: una educación en la que el sujeto se pierde por las pretensiones de objetividad derivadas de entender que el espíritu positivista es la única alternativa.

En el modelo, es fundamental que la ética supere la tradicional 47. Ética como declaración del ser ético. Se precisa hacer los procedimientos, discurso dominante ejecutar los proyectos, tomar decisiones éticas. El discurso dominante de la ética en el modelo educativo de la Universidad está en el dominio del hacer.

"El mejor lenguaje, aquel que permite la plena manifestación del sujeto, es armónico, proporcionado, mantiene la correspondencia de las cosas que conforman un conjunto. Por ello encontramos en el arte, en la literatura, en la poesía las mejores muestras de él. De aquí que el discurso que prima en el mundo

\section{Estética} subjetivo es estético; y las ciencias que se encargan de esta zona como discurso dominante del mundo de la vida se denominan histórico-hermenéuticas. Lo que se obtiene con estos conocimientos es la identidad personal, la posibilidad de mostrar lo propio, aquello que me hace diferente de los otros, pero que me permite estar con los otros. La ausencia del conocimiento histórico-hermenéutico hace que el sujeto se pierda, que naufrague en la inconsciencia propia de ciertas psicopatologías" (Unigarro, 2017, p. 19). 
Término /

Concepto

50. Didáctica

\section{Significado / Interpretación en el modelo}

Jürgen Habermas (Düsseldorf, 18 de junio de 1929) es un filósofo y sociólogo alemán reconocido en todo el mundo por sus trabajos en filosofía política, ética y teoría del derecho, así como en filosofía del lenguaje. Gracias a una actividad regular como profesor en universidades extranjeras, especialmente en Estados Unidos, así como por la traducción de sus trabajos más importantes a más de cuarenta idiomas, sus teorías son conocidas, estudiadas y discutidas en el mundo entero. Habermas es el miembro más eminente de la segunda generación de la Escuela de Frankfurt y uno de los exponentes de la teoría crítica desarrollada en el Instituto de Investigación Social. Entre sus aportes destacan la construcción de la teoría de la acción comunicativa, la ética del discurso y la teoría de la democracia deliberativa (Wikipedia, s. f. b). La teoría crítica formulada por Jürgen Habermas retoma conceptos de Husserl sobre el mundo de la vida para estructurar una propuesta epistemológica que se convierte en la piedra angular de la pedagogía crítica (en la formulación del modelo educativo). También se muestra la concepción de la educación como acción comunicativa y su énfasis en el diálogo entre quienes enseñan y quienes aprenden (Unigarro, 2017, p. 9).

"En algunos casos, se encuentra que la palabra 'pedagogía' se asocia al acto de enseñar, y en este sentido se convierte en sinónimo de 'didáctica'. En el presente texto no es así. Es necesario precisar aquí que el concepto de 'pedagogía' se entiende como la disciplina que tiene por objeto de estudio la educación. Independientemente de que algunos le asignen estatuto de ciencia, como lo muestra Bórquez (2006), es claro que el acto educativo es lo que, en esencia, estudia la pedagogía. Así, entonces, lo pedagógico surge cuando se piensa en lo que supone educar: '... aunque se considere a la pedagogía como ciencia, disciplina, teoría, reflexión o estudio del hecho educativo, esta siempre aparece vinculada con la educación. Por consiguiente, la actividad de la pedagogía siempre se desprende de su objeto, que es la educación' (Bórquez, 2006, p. 87)". (Unigarro, 2017, p. 29)

El Modelo Educativo Crítico con Enfoque de Competencias fue creado para la Universidad Cooperativa de Colombia por su autor, el director nacional de Gestión de Programas, Manuel Unigarro Gutiérrez. En el desarrollo de algunos apartes, han participado expertos como Daniel Bogoya y Milton Vásquez, entre 
Término /

Concepto

\section{Significado / Interpretación en el modelo}

otros. Y en su discusión para la implementación, un numeroso equipo que incluye desde decanos nacionales, hasta profesores y empleados.

El modelo fue acogido por Acuerdo Superior 057 del 15 de septiembre de 2015, con un nombre transitorio: "modelo de gestión por competencias". Desde entonces el desarrollo y la implementación del modelo han evolucionado en la estructura, el contenido y la denominación.

La rúbrica para la evaluación de estados de desarrollo de competencias en el modelo educativo de la Universidad Cooperativa de Colombia es una realización propia del autor del modelo y

52. Institucionalidad de la rúbrica sus colaboradores. Representa una forma de enseñar y evaluar, coherente con los principios del Proyecto Institucional.

Con base en la precisión y coherencia que se impone desde la lexicografía del modelo, se dice: "realizar la rúbrica"; no producir, no elaborar, porque se quiere denotar que es como una obra de arte, cine, pintura, literatura... que implica talento, conocimiento y habilidad.

Código, construcción de relaciones de significado entre fonemas

53. Idioma y grafemas, que se usa en formato escrito o en formato oral; es el idioma el que tiene una gramática que lo ordena con reglas propias, independientemente del formato.

Capacidad humana compleja que integra el sentido del oído y la capacidad del habla, especialmente, con otras capacidades 54. Lenguaje como memoria, abstracción, pensamiento, locución, para crear por medio de la razón y la imaginación una combinación infinita de expresiones con sentidos lógico, estético y ético.

Fenómeno social y cultural que utiliza el idioma y el lenguaje para construir una cosmogonía colectiva a partir de tradiciones, cos-

55. Lengua tumbres, mitos, interpretaciones, léxicos propios, códigos semánticos, roles sociales, entre otros; la lengua transmite una forma de habitar en espacio y tiempo de la cultura. Cuando muere una lengua, muere una forma de comprender y vivir el universo.

Tiene una primera acepción como función oral: hablar. Y tiene 56. Habla otra como particularidad cultural de esa oralidad cuando se refiere a un origen: habla paisa, costeña, llanera. 
Término /

Concepto

\section{Significado / Interpretación en el modelo}

57. Sintaxis

como

fundamento

lingüístico

El fundamento lingüístico es la forma como se estructura el saber, el conocimiento, en un discurso, en relación con la lengua. En el caso de la sintaxis, es el discurso de la lógica, el mínimo uso de metáforas, la economía y contundencia de las palabras y la estabilidad de los conceptos, que hacen que el saber se vea en el hacer y en el ser.

La interpretación es la clave de este concepto. Palabras, signos,

58. Semántica como símbolos, indicios. El acervo de conocimiento y experiencia da

fundamento lingüístico a la persona la posibilidad de ampliar las posibilidades de interpretar de forma acertada. En el modelo se relaciona directamente con la actitud, porque el ser humano interpreta desde lo que es y como se muestra.

En este modelo educativo, un alumno solo aprenderá lo que requiere para ejercer su profesión en el mundo de la vida de 59. Pragmática como forma competente. Y no es poco, no debe entenderse de forma

fundamento peyorativa. Todo lo contrario, educarse en los tres elementos de lingüístico la competencia, SER, SABER, y HACER, requiere mucho más esfuerzo y dedicación, mucho más si se considera que lo hace con base en estados de desarrollo establecidos con altos estándares de desempeño.

"El método empírico-analítico es un modelo del método científico que se basa en la experimentación y la lógica empírica, que,

60. Ciencias empíricoanalíticas junto a la observación de fenómenos y sus análisis estadísticos, es el más usado en el campo de las ciencias naturales y en las ciencias sociales. El término "empírico" deriva del griego [...] en pruebas, es decir, llevando a cabo el experimento. Por lo tanto, los datos empíricos son sacados de las pruebas acertadas y los errores, es decir, de experiencia" (Wikipedia, s. f. c.).

Este es el método de las humanidades que busca interpretar y 61. Ciencias históricohermenéuticas comprender los motivos internos de la acción humana, mediante procesos libres, no estructurados, sino sistematizados, a partir de una trayectoria documentada y analizada. Su origen es la filosofía humanista. La hermenéutica es técnica, arte y filosofía de los métodos. 


\section{Término / Concepto}

62. Ciencias crítico-sociales

\section{Significado / Interpretación en el modelo}

El conocimiento de las ciencias crítico-sociales surgió como respuesta al positivismo, cultivado por ciencias de corte emancipador como economía, sociología, politología, educación. Su visión del deber y del derecho da al ser humano unas condiciones de equidad desde la oportunidad como base de la solidaridad.

63. Racionalidad

como

condición

de éxito

La racionalidad como condición de éxito en el desarrollo de una competencia es la capacidad de pensar, analizar evaluar, entender y comprender de forma consistente el mundo de la vida desde la perspectiva de la lógica y la naturaleza.

"Conquistar la autonomía [...] entendida esta en el sentido kantiano y que se orienta a que cada persona pueda pensar por sí

64. Autonomía como misma, expresar lo que piensa y obrar en consecuencia. Se puecondición de éxito de afirmar que esa tríada que define la autonomía está íntimamente relacionada con los constitutivos del Mundo de la vida: pensar por sí mismo tiene que ver con encontrar el sentido, lo cual es el aporte central del discurso fundamentalmente lógico de las ciencias empírico-analíticas" (Unigarro, 2017, p. 20).

"La solidaridad, la adhesión a la causa de los otros, es la que hace posible vivir el mundo intersubjetivo. De allí que el discur-

65. Solidaridad como condición de éxito so que prima en este mundo sea el ético y que las ciencias que construyen el conocimiento propio de esta zona del mundo de la vida se denominen crítico-sociales. Con estos conocimientos, se obtienen unas relaciones interpersonales reguladas que favorecen la articulación entre los intereses individuales y los colectivos" (Unigarro, 2017, p. 20).

"Desaparece el Mundo de la vida y permanece solamente el mundo natural, lo que deja a la persona existiendo en la esfera de la 'actitud natural', en la ausencia de reflexión. De allí que el 66. Pérdida de sentido afincamiento en las perspectivas del positivismo y del psicologismo como caminos para el conocimiento conducen a la pérdida de sentido, a la falsa objetividad, a la ciencia sin consciencia. Justamente, la intención de recuperar el sentido, y así el mundo de la vida, es lo que origina la fenomenología trascendental, que es la propuesta de Husserl" (Unigarro, 2017, pp. 16-17). 
Término /

Concepto

\section{Significado / Interpretación en el modelo}

En el contexto del modelo educativo, es un conjunto de desórdenes de tipo psicológico que afectan la capacidad del alumno de

67. Psicopatología comprenderse en el mundo de forma crítica, es decir, con sentido determinante de autenticidad. No logra integrarse como ser humano autónomo, con un rol claro y un ordenamiento lógico de sus potencialidades.

Se denomina anomia (del griego àvopia / anomia: prefijo $\ddot{\alpha}$ / a "ausencia de" y vónos/ nomos "ley, orden, estructura") a la falta

68. Anomia de normas o a la incapacidad de la estructura social de proveer a ciertos individuos de lo necesario para lograr las metas de la sociedad. El término es utilizado en sociología y ciencias sociales (Wikipedia, s. f. d.).

Es el resultado de comprender el mundo de la vida en función de los fenómenos de la naturaleza. Saber discernir los límites de lo 69. Saber válido que puede ser una explicación científica creíble y algo que no lo es porque involucra incertidumbres, ambigüedades y opiniones de forma intencional.

Es el resultado de fortalecer la subjetividad, su autonomía, el 70. Identidad interés práctico, la estética, con el conocimiento histórico-herpersonal menéutico de sí mismo. Saber su origen, su lugar, su trayectoria, su potencial y su proyección.

\begin{tabular}{ll}
\hline $\begin{array}{l}\text { 71. Relaciones } \\
\text { personales } \\
\text { reguladas }\end{array}$ & $\begin{array}{l}\text { Son las relaciones sociales resultantes de aplicar una habilidad } \\
\text { en forma ética, en el mundo interpersonal, con sentido de la } \\
\text { solidaridad y la pragmática. }\end{array}$ \\
\hline $\begin{array}{l}\text { 72. Interés } \\
\text { técnico }\end{array}$ & $\begin{array}{l}\text { turales, lo hacen para explicar los fenómenos del mundo de la } \\
\text { vida, de manera lógica y científica. Este es el tipo de conocimien- } \\
\text { to que se construye aquí, de tipo empírico analítico a partir del } \\
\text { trabajo. }\end{array}$ \\
\hline $\begin{array}{l}\text { 73. Interés } \\
\text { práctico }\end{array}$ & $\begin{array}{l}\text { Este es el interés del conocimiento que se construye en el mun- } \\
\text { do intersubjetivo, en la interacción de los sujetos, el que les sirve } \\
\text { para explicarse y al mismo tiempo para comprender las explica- } \\
\text { ciones de los demás en las relaciones intersubjetivas. El interés } \\
\text { práctico es comprender y comprenderse en el mundo. }\end{array}$ \\
\hline
\end{tabular}


Término /

Concepto

\begin{tabular}{|c|c|}
\hline $\begin{array}{l}\text { 74. Interés } \\
\text { emancipatorio }\end{array}$ & $\begin{array}{l}\text { Es el interés de las ciencias crítico-sociales, que buscan que el } \\
\text { sujeto descubra que él necesita a los demás y los demás lo nece- } \\
\text { sitan a él; que la subjetividad resulta de la construcción que se } \\
\text { hace a partir del encuentro con otras subjetividades. Por eso el } \\
\text { reconocimiento del otro tiene un interés emancipador (Uniga- } \\
\text { rro, 2017, p. 20). }\end{array}$ \\
\hline $\begin{array}{l}\text { 75. Interdisci- } \\
\text { plinariedad }\end{array}$ & $\begin{array}{l}\text { Es el fenómeno que surge a partir de integrar conocimientos } \\
\text { procedentes de los tres mundos del mundo de la vida, de las tres } \\
\text { categorías de ciencias que integran los elementos de la compe- } \\
\text { tencia y la competencia misma. }\end{array}$ \\
\hline 76. Husserl, E. & $\begin{array}{l}\text { Edmund Gustav Albrecht Husserl (Prossnitz, } 8 \text { de abril de } \\
\text { 1859-Friburgo, } 27 \text { de abril de 1938) fue un filósofo y matemático } \\
\text { alemán, fundador de la fenomenología trascendental, que es } \\
\text { ante todo un proyecto de renovación de la filosofía para hacer } \\
\text { de ella una ciencia estricta y una empresa colectiva. Como for- } \\
\text { ma de entender la filosofía, la fenomenología asume la tarea de } \\
\text { describir el sentido que el mundo tiene para nosotros antes de } \\
\text { todo filosofar. }\end{array}$ \\
\hline 77. Heidegger, M. & $\begin{array}{l}\text { Martin Heidegger nació en Messkirch, Baden-Wurtemberg, Ale- } \\
\text { mania, el } 26 \text { de septiembre de } 1889 \text { y murió en Friburgo de Bris- } \\
\text { govia, Baden-Wurtemberg, Alemania, el } 26 \text { de mayo de } 1976 \text {. Fue } \\
\text { un filósofo alemán considerado, junto con Edmund Husserl y } \\
\text { Ludwig Wittgenstein, como el pensador más influyente del siglo } \\
\text { xx y de la filosofía contemporánea. Tras sus inicios en la teolo- } \\
\text { gía católica, desarrolló una filosofía que influyó en campos tan } \\
\text { diversos como la teoría literaria, social y política, el arte y la es- } \\
\text { tética, la arquitectura, la antropología cultural, el diseño, el eco- } \\
\text { logismo, el psicoanálisis y la psicoterapia. Entre sus aportes más } \\
\text { destacados estableció una clara relación entre el lenguaje y el } \\
\text { conocimiento: "La persona se muestra mediante el lenguaje [...] } \\
\text { solamente el lenguaje hace posible que una persona se diga, se } \\
\text { manifieste". En el mismo sentido que afirmara Heidegger (2000), } \\
\text { "el ser se encarna en el lenguaje" (Unigarro, 2017, p. 18). }\end{array}$ \\
\hline $\begin{array}{l}\text { 78. Chomsky, } \\
\text { N.; Greimas, A. } \\
\text { y Hymes, D. }\end{array}$ & $\begin{array}{l}\text { En este modelo educativo, "el concepto de competencia se nutre } \\
\text { de los pensamientos de Noam Chomsky, Algirdas Greimas y Dell } \\
\text { Hymes. Los tres abordaron el tema desde la Lingüística. }\end{array}$ \\
\hline
\end{tabular}

\section{Significado / Interpretación en el modelo}

Es el interés de las ciencias crítico-sociales, que buscan que el sujeto descubra que él necesita a los demás y los demás lo necehace a partir del encuentro con otras subjetividades. Por eso el reconocimiento del otro tiene un interés emancipador (Uniga- 
Término /

Concepto

\section{Significado / Interpretación en el modelo}

"Chomsky (1972) plantea que las personas van nutriendo el lenguaje, y que en la medida en que adquieren ciertos códigos propios de su campo, pueden producir una infinidad de otros más. Cada profesión tiene unos códigos, y quien pretenda ejercerla debe apropiarse de ellos. La manera como los códigos se van articulando en cada profesión y van configurando su marco teórico, su discurso propio, se llama sintaxis. Lo sintáctico se relaciona directamente con la dimensión cognitiva, la cual consiste en apropiar unos códigos del campo de quien los estudia. Greimas (1973) complejiza el planteamiento de Chomsky al introducir el asunto de la manera como las personas van asignando significados distintos y cómo, entonces, los códigos no van en la misma dirección siempre. Por ello deben hacer un ejercicio de argumentar para sustentar los significados que van construyendo. Esto tiene que ver con la semántica y se relaciona con lo actitudinal, con la manera como la persona se muestra. Finalmente, Hymes (1996) insiste en que la sintaxis y la semántica no son el punto de llegada de la competencia. Además de tener unos códigos y unas comunidades semánticas, es indispensable pasar al campo del uso. Se refiere el autor a la pragmática y está en directa relación con la dimensión procedimental de la competencia, con la esfera del hacer" (Unigarro, 2017, pp. 50-51).

Teun Adrianus van Dijk, es un lingüista neerlandés, de quien el modelo toma el concepto "contexto". Su tesis doctoral sobre la gramática del texto le impulsó a crear con otros intelectuales el Análisis crítico del discurso, una aplicación práctica que permite descubrir las sutilezas de lo que no se expresa de manera intencional (Van Dijk, s. f.).

"Toda esta articulación armónica que se ha venido presentando,

79. Van Dijk, T. esta tríada de ser-saber-hacer opera, para que sea competencia, siempre en contextos concretos. El contexto hace referencia a un entorno físico, cultural, político en el que se considera un hecho. Pero el contexto no es algo externo al sujeto. El contexto, ese entorno en el que las cosas suceden, resulta siendo una construcción intersubjetiva a partir de los conocimientos, las convicciones y las valoraciones de los sujetos. Un mismo entorno puede ser considerado de diversas maneras por individuos diferentes" (Unigarro, 2017, p. 54). 
Término /

Concepto

80. Bloom, B.

\section{Significado / Interpretación en el modelo}

Benjamin Bloom fue psicólogo y pedagogo nacido en Estados Unidos en 1913, reconocido por haber planteado la clasificación de los objetivos de la educación, apoyado en la taxonomía de los verbos, y por otros aportes en materia de aprendizaje y desarrollo cognitivo. Su clasificación tiene seis niveles de complejidad creciente. Bloom fundamentó su trabajo en técnicas y principios tomados del conductismo y el cognitivismo.

La taxonomía de Bloom se aplicó en los primeros desarrollos del modelo educativo crítico de la Universidad, especialmente en la formulación de competencias. Luego, con los logros y avances del equipo de desarrollo, se adoptó la taxonomía de Biggs y Collis, conocida como taxonomía solo.

Nota. Elaboración propia del Observatorio para la Gestión de Conocimiento, 2019.

Tabla 2. Preguntas y secuencia de definiciones que las responden

\begin{tabular}{lc} 
Pregunta & $\begin{array}{c}\text { Secuencia de definiciones } \\
\text { para una aproximación }\end{array}$ \\
\hline ¿Cuál es la diferencia entre evaluar y calificar? & 18,23 y 24 \\
\hline ¿Qué es una competencia? & 7,13 y 18 \\
\hline $\begin{array}{l}\text { ¿Por qué la estética es el discurso dominante en la } \\
\text { dimensión del ser? }\end{array}$ & 48 y 40 \\
\hline $\begin{array}{l}\text { ¿Por qué la ética es el discurso dominante en la } \\
\text { dimensión del hacer y no del ser? }\end{array}$ & 47 y 41 \\
\hline ¿Cuál es el rol del profesor en el modelo educativo? & $8,14,18$ y 19 \\
\hline \begin{tabular}{l} 
¿Cuál es la diferencia entre alumno y estudiante? \\
\hline ¿Cuál es la relación entre competencia y contexto?
\end{tabular} & $7,16,18$ y 19 \\
\hline $\begin{array}{l}\text { ¿Cuál es la diferencia entre evidencia, } \\
\text { indicador y evaluación? }\end{array}$ & 38,19 y 20 \\
\hline
\end{tabular}

Nota. Elaboración del Observatorio para la Gestión de Conocimiento, 2019. 


\section{CONCLUSIONES}

1. Este glosario fortalece el afianzamiento del proyecto institucional, específicamente en lo que declara sobre la adopción del Modelo Educativo Crítico con Enfoque de Competencias, porque desarrolla definiciones, aporta comentarios y relaciona conceptos clave.

2. Un mismo horizonte de sentido conceptual sobre aspectos determinantes del modelo transitan hacia todos los ámbitos académicos y administrativos de la institucionalidad; por lo tanto, se propicia una disminución de la polisemia, no solo en los documentos y producción formal, sino en la conversación espontánea.

3. La comprensión facilita la apropiación. En este sentido, el presente glosario y sus dos formas de uso contribuyen a elevar la comunicación acerca de la implementación del Modelo Educativo Crítico con Enfoque de Competencias, especialmente para quienes se aproximan por primera vez a él.

4. Este glosario representa un punto de partida para continuar la construcción de otros conceptos y perspectivas sobre la teoría y la pedagogía críticas, que surjan de la práctica del modelo en ambientes propicios para el aprendizaje.

5. Los procesos de gestión de conocimiento se enriquecerán -en particular, este glosario- en futuras ediciones, en la medida en que nuevas rúbricas propongan otros verbos, otras acepciones, otros conceptos y otros procedimientos cognitivos; en la medida en que la tecnología, la inteligencia artificial y la interdisciplinariedad ofrezcan alternativas nuevas. 


\section{REFERENCIAS}

Biggs, J. B. y Collis, K. F. (1982). Evaluating the Quality of Learning: The solo Taxonomy. Londres: Academic Press.

Blog Definición. (s. f.). Glosario. Recuperado el 21 de agosto de 2019, de https:// definicion.de/glosario/

Real Academia de la Lengua. (RAE). (2014). Diccionario de la lengua española

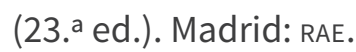

Wikipedia. (s. f. a.). Taxonomía. Recuperado de https://es.wikipedia.org/wiki/ Taxonomía

Wikipedia. (s. f. b.). Jürgen Habermas. Recuperado de https://es.wikipedia.org/ wiki/J\%C3\%BCrgen_Habermas

Wikipedia. (s. f. c.). Método empírico-analítico. Recuperado de https://es.wikipedia. org/wiki/M\%C3\%A9todo_emp\%C3\%ADrico-anal\%C3\%ADtico

Wikipedia. (s. f. d.). Anomia (ciencias sociales). Recuperado de https://es.wikipedia. org/wiki/Anomia_(ciencias_sociales)

Unigarro, M. (2017). Un Modelo Educativo Crítico con Enfoque de Competencias. Bogotá: Ediciones Universidad Cooperativa de Colombia.

Van Dijk, T. (s. f.). Blog Discurso en Sociedad. Recuperado de http://www.discursos. org/ 


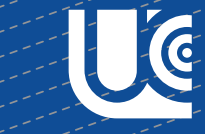

UN I V-ERSIDA-D

COOPERATIVA

DE-COLO M B IA
Pizoma
GREEN

PÁPERS 